\title{
A Proposal for Upgrading the National-Scale Soil Geochemical Database for the United States
}

The most requested data from the U.S. Geological Survey's (USGS) National Geochemical Database is a set of 1,323 soil samples. Why? Consider the following examples:

Example 1-Imagine for a moment that you are employed by an environmental regulatory agency of either the Federal or a State Government. Your assignment is to establish a "remediation value" for arsenic in soil at a contaminated site where a wood preservative facility once operated. Current arsenic values in soils at the facility range from 15 to $95 \mathrm{ppm}$ and you must decide the concentration of arsenic that is acceptable after remediation efforts are completed. Scientists refer to the natural or native concentration of an element in soils as the "background concentration." Given the fact that arsenic occurs naturally in all soils, how would you determine the background concentration of arsenic in soils for this particular area?

Example 2-Your environmental consulting firm has been assigned to work with a team of specialists conducting a risk-based assessment of land contaminated with lead, zinc, and cadmium from a metal foundry. The assessment would determine the likelihood of adverse health or ecological effects caused by the contaminants. Again, an important part of this determination is, "What is the background concentration of these elements in the soil?"

What data are available for persons responsible for making the determinations of background concentrations for soils contaminated with potentially toxic metals? The most-often-quoted data set for background concentrations of metals and other trace elements in soil of the conterminous United States consists of only 1,323 samples collected during the 1960s and 1970s by the U.S. Geological Survey (Boerngen and Shacklette, 1981; Shacklette and Boerngen, 1984). (There is a similar data set for Alaska (Gough and others, 1984, 1988)). Samples for the "Shacklette data" were collected from a depth of about $1 \mathrm{ft}$, primarily from noncultivated fields having native vegetation, and samples were analyzed for more than 40 elements. Data in this study represent about one sample per 2,300 $\mathrm{mi}^{2}$, indicating that very few samples were collected in each State. For example, the State of Arizona is covered by only 47 samples, and Pennsylvania has only 16. Despite the low number of samples, this data set is still being used on a regular basis to determine background concentrations of metals in soil to aid in remediation or risk-based assessments of contaminated land.

The only other national-scale soil geochemical data set for the United States was generated by the Natural Resources Conservation Service (NRCS), formerly the Soil Conservation Service (Holmgren and others, 1993). This data set consists of 3,045 samples of agricultural soil collected from major crop-producing areas of the conterminous United
Figure 1. Map of arsenic distribution in soils and other surficial materials of the conterminous United States based on 1,323 sample localities as represented by the black dots.

States. The primary purpose of this study was to assess background levels of lead and cadmium in major food crops and in soils on which these crops grow. Thus, the samples were only analyzed for five metals-lead, cadmium, copper, zinc, and nickel.

The Shacklette data set allows us to produce geochemical maps for specific elements, such as that shown on figure 1 for arsenic (Gustavsson and others, 2001). A map produced from such sparse data points obviously carries a large degree of uncertainty with it and does not have the resolution needed to answer many of the questions raised by land-management and regulatory agencies, earth scientists, and soil scientists. An example of the poor data set resolution is illustrated for Pennsylvania (fig. 2). The State is divided into major soil taxonomic units referred to as Suborders (Soil Survey Staff, 1999). Suborders group similar soil types in any region. The dots represent the sample points from the Shacklette data set. The few sample points shown on figure 2 illustrate that this data set would be inadequate for someone who must define the arsenic content of a given soil. At this time, no data set exists that will allow us to make these kinds of determinations.

The USGS and NRCS are currently studying the feasibility of a national-scale soil geochemical survey that will increase the sample density of the Shacklette data set by at least a factor of 10 . This project, called Geochemical Landscapes, began in October 2002. The first 3 years will be devoted to determining how such a survey should be conducted. Therefore, we are actively soliciting input from potential customers of the new data. Interested members of the private sector, government, or academic communities 
are asked to provide input on a design for sampling the nation, establishing sampling and analytical protocols, and the types of products that will be most useful. For further information about this project or about available data sets, please contact any of the following:

\section{David B. Smith}

U.S. Geological Survey

Box 25046, Mail Stop 973

Denver Federal Center

Denver, CO 80225-0046

303-236-1849

dsmith@usgs.gov

Martin B. Goldhaber U.S. Geological Survey Box 25046, Mail Stop 973

Denver Federal Center

Denver, CO 80225-0046

303-236-1521

mgold@usgs.gov

Michael A. Wilson

Natural Resources Conservation Service

Federal Building, Room 152

Mail Stop 41

100 Centennial Mall North

Lincoln, NE 68508-3866

402-437-4134

mike.wilson@nssc.nrcs.usda.gov

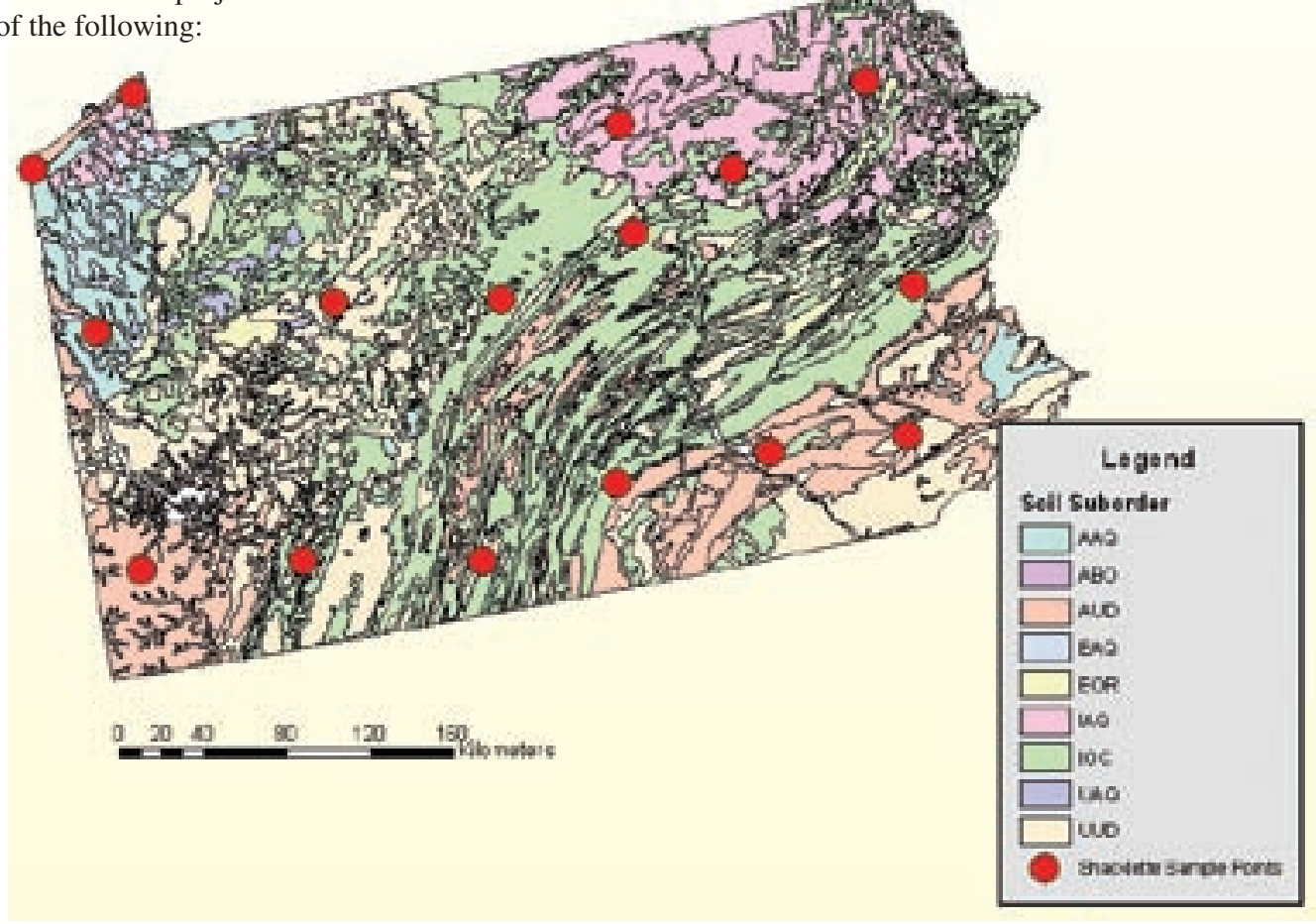

Figure 2. Map of Pennsylvania showing soil Suborders and sampling sites from Shacklette and Boerngen (1984).

\section{Pennsylvania}

Rebecca Burt

Natural Resources Conservation Service

Federal Building, Room 152

Mail Stop 41

100 Centennial Mall North

Lincoln, NE 68508-3866

402-437-5133

rebecca.burt@nssc.nrcs.usda.gov

\section{References Cited}

Boerngen, J.G., and Shacklette, H.T., 1981, Chemical analyses of soils and other surficial materials of the conterminous United States: U.S. Geological Survey Open-File Report 81-197, 143 p.

Gough, L.P., Peard, J.L., Severson, R.C., Shacklette, H.T., Tompkins, M.L., Stewart, K.C., and Briggs, P.H., 1984, Chemical analyses of soils and other surficial materials, Alaska: U.S. Geological Survey Open-File Report 84-423, 77 p.

Gough, L.P., Severson, R.C., and Shacklette, H.T., 1988, Element concentrations in soils and other surficial materials of Alaska: U.S. Geological Survey Professional Paper 1458, 53 p.

Gustavsson, N., Bølviken, B., Smith. D.B., and Severson, R.C., 2001, Geochemical landscapes of the conterminous United States-New map presentations for 22 elements: U.S. Geological Survey Professional Paper 1648, 38 p. [http:// geology.cr.usgs.gov/pub/ppapers/p1648/].
Holmgren, G.G.S, Meyer, M.W., Chaney, R.L., and Daniels, R.B., 1993, Cadmium, lead, zinc, copper, and nickel in agricultural soils of the United States of America: Journal of Environmental Quality, v. 22, p. 335-348.

Shacklette, H.T., and Boerngen, J.G., 1984, Element concentrations in soils and other surficial materials of the conterminous United States: U.S. Geological Survey Professional Paper 1270, 105 p.

Soil Survey Staff, 1999, Soil taxonomy: A basic system of soil classification for making and interpreting soil surveys: Washington, D.C., U.S. Government Printing Office, U.S. Department of Agriculture-Soil Conservation Service Agriculture Handbook 436, 2nd ed. 